\title{
Amadeus
}

International Multidisciplinary Journal ISSN 2525-8281

V.2, N. 4. Jul./2018 - 10.14295/aimj.v2i4.37. ISSN 2525-8281

\section{THE PSYCHOLOGICAL IMPACT IN WOMEN AFTER MASTECTOMY WITH AND WITHOUT IMMEDIATE MAMMARY RECONSTRUCTION}

Bárbara Torquato Alves ${ }^{1}$; Antonio Marlos Duarte de Melo $^{2}$;

Sâmia Israele Braz do Nascimento ${ }^{1}$; José Maria Sousa Neto ${ }^{l}$; Itamar Alves Araújo'; Teresa Manuela Oliveira Puentes $^{1}$; Patrícia Sobral Luna Quidute

\begin{abstract}
Breast cancer is a very common pathology in the female environment, being the second largest cause of neoplasia in Brazil. Surgical treatment with mastectomy is seen as resolving in most cases, but breast reconstruction is crucial for improving the psychological aspects of the patient, since the removal of the breast without the oncoplastic can trigger emotional, stress and sadness problems. Breast reconstruction may be immediate, when performed in the postoperative period of the mastectomy, or late, when performed at any time postoperatively. The mastectomy, in isolation, can leave the patient with visible scars, aesthetic deformities in the breasts, causing greater psychological problems such as anxiety, depression, panic syndrome, distortion of body self-image, as well as sexual dysfunctions. Thus, there are still gaps in knowledge in the analysis of the psychological impact and, of course, new researches that analyze the psychological factor in mastectomized women with and without immediate breast reconstruction are crucial to better work the moment of vulnerability that these patients are going through.
\end{abstract}

Keywords: Mastectomy; Breast cancer; Oncoplastic; Breast reconstruction; Psychological problems.

\footnotetext{
${ }^{1}$ Faculty of Medicine Estacio of Juazeiro do Norte, Juazeiro do Norte, Ceara, Brazil.

2 Institute of Mama of Cariri, Juazeiro do Norte, Ceara, Brazil.

${ }^{3}$ City Hall of Custodia, Custodia, Pernambuco, Brazil.

Corresponce Author: Barbara Torquato Alves. Estacio-FMJ. Medicine course.

E-mail: btorquatoalves@gmail.com
} 


\section{Introduction}

Breast Cancer is the most common malignant neoplasm among women in Brazil and in the world after non-melanoma skin cancer. It is estimated that the year 2018 has an incidence of 59,700 cases in Brazil. Despite all the mobilization that has been carried out in the country in the last years for the tracking of the disease, including campaigns of great media acceptance, such as "Outubro Rosa / Pink October", the mortality due to breast cancer remains high, resulting in the death of 14,388 women in the country in the year 2013. One of the therapies most used for the treatment of this disease is mastectomy, associated or not with the withdrawal of lymph nodes. ${ }^{1}$

\section{Emotional issues after mastectomy}

Immediate breast reconstruction can be done immediately after mastectomy, at the same surgical time, or at any other time in the late postoperative period (late mammary reconstruction). ${ }^{2}$

Receiving the diagnosis of breast cancer is something that generates transformations in a woman's life, since the breasts are important for the female self-image. The breasts refer women to their femininity, sexuality and fertility. The discovery of a disease in such a gland as well as the withdrawal of this as a form of treatment lead the woman to a high level of stress, since this will face a series of challenges, both physical and psychic, such as changes in appearance and body disfigurement, as well as conflicts over the imaginary of their mortality. Mastectomy alone can leave the patient with visible scars, deformities or asymmetries in the region and the psychological impact of these changes is reflected in the development of psychic pathologies such as anxiety, depression, panic syndrome, distortion of body selfimage, as well as sexual dysfunction. The feelings associated with this picture are of vulnerability, sadness and fear. , $3,4^{2}$

In the age of imaging and oncoplastic examinations, mutilating surgeries are no longer justified in the vast majority of cases of breast cancer, since issues relating to aesthetics and patients' mental health are present throughout the course of treatment. Failure to identify and 
treat complications related to these issues can have an impact on the quality of life of women. ${ }^{3,5}$

In this context, breast neoplasm is an important pathology from both an epidemiological and a social point of view. In view of these problems related to the surgical treatment of breast cancer, in an attempt to soften them, the National Congress sanctioned the Law 12.802 in 2013, which obliges the Sistema 'Unico de Saúde - SUS (the public health system of Brazil) to perform the restorative surgery soon after the withdrawal of the breast. Previously, Law 9.797 already guaranteed this right to women, but did not specify the time in which this procedure should be performed. In 2015 the Brazilian Society of Mastology met to define consensus on oncoplastic surgery and breast reconstruction. It was established that this type of surgery is a set of practices with a specific purpose that is the improvement of the oncological and esthetic parameters of breast cancer. In addition, it was agreed by consensus that immediate reconstruction can be safely indicated for the majority of women who will undergo mastectomy. ${ }^{5}$

Although it is a subject of great social relevance and widely debated internationally, there are still gaps in knowledge in the analysis of the psychological impact suffered by the mastectomized women in the world. Some of the barriers encountered by researchers are the frequent impossibility of conducting randomized, double-blind investigations in these cases, the identification of significant changes that are not easily identified when very recent, and the possibility that responses may change when they involve irreversible disabilities, vulnerabilities, and changes of concepts.$^{3}$

In addition, the literature has restricted information on prehospital psychosocial functionality and aesthetic satisfaction in the early postoperative period of breast cancer. Understanding the psychological impact of a mastectomy surgery and the interference that a breast reconstruction can cause in this process is critical for the health professional to be able to inform their patients about their treatment and the changes caused by the procedure so that decisions can be taken in a shared way, valuing the physical and mental health of patients. Clarification on potential bodily changes, as well as on self-perception of the body, interference with well-being, quality of life and sexual function, and possible psychological disorders are fundamental for successful treatment. ${ }^{2,6}$ 
Research that analyzes the psychological factor in mastectomized women with and without immediate breast reconstruction is essential to provide health professionals with the knowledge necessary to better work the moment of difficulty that their patients are facing. ${ }^{2,6}$

\section{Final considerations}

Therefore, in the last years, the debate about the psychological aspects that occur in the woman after the mastectomy by breast cancer has grown. This pathology already has emotional problematization, and the treatment for the disease can not cause more disorders for the patient due to the basal fragility of the disease.

Thus, there are gaps in this knowledge and new studies are needed to address the importance of oncoplastics in post-mastectomy and this may be crucial in determining the woman who, once cured of the disease by mastectomy, can appreciate herself through breast reconstruction, in self-image and drastically decrease the social negativity that depression, emotional problems, and sexual dysfunction can cause in the post-surgical period.

\section{References}

1.INCA, Tipos de Câncer, 2018. Available in: http://www2.inca.gov.br/wps/wcm/connect/tiposdecancer/site/home/mama>. Access: 28.06.2018.

2. METCALFE, Kelly A. et al. A Prospective Study of Mastectomy Patients With and Without Delayed Breast Reconstruction: Long-Term Psychosocial Functioning in the Breast Cancer Survivorship Period. Journal of Surgical Oncology, v.111, p. 258-264, dez. 2014.

3. DAUPLAT, J. et al. Quality of life after mastectomy with or without immediate breast reconstruction. BJS Society Ltd, v.104, p. 1197-1206, abr. 2017.

4. MENEN, Rhiana S.; HUNT, Kelly K. Considerations for the Treatment of Young Patients with Breast Cancer. The Breast Journal, v.22, n.6, p. 667-672, 2016. 
5. URBAN, Cicero. et al. Cirurgia oncoplástica e reconstrutiva da mama: Reunião de Consenso da Sociedade Brasileira de Mastologia. Rev Bras Mastologia, Rio de Janeiro, v.25, n.4, p. 118-124, 2015.

6. JORGENSEN, L. et al. The experience of distress in relation to surgical treatment and care for breast cancer: An interview study. European Journal of Oncology Nursing, v.19, p. 612$618,2015$.

\section{How to cite this article (APA format):}

Alves, Bárbara Torquato; Melo, Antonio Marlos D. de; Nascimento, Sâmia Israele B. do; Sousa Neto, José Maria; Araújo, Itamar Alves; Puentes, Teresa Manuela O.; Quidute, Patrícia Sobral L. (2018). The Psychological Impact in Women after Mastectomy with and Without Immediate Mammary Reconstruction. Am In. Mul J, 2 (4), p. 112-116.

Received: 07/04/2018.

Accepted: 07/06/2018. 